\title{
RAZONES Y ESTRATEGIAS DE LA DESCENTRALIZACIÓN EDUCATIVA: UN ANÁLISIS COMPARADO DE ARGENTINA Y CHILE
}

\section{Alejandra N. Candia}

SÍNTESIS: La globalización ha transferido al ámbito del debate educativo un nuevo repertorio de conceptos y de valores económicos tales como privatización, productividad, eficiencia, evaluación de rendimiento, desregulación, participación local en la toma de decisiones, competencia y libertad de elección por parte de los consumidores (Burbules y Torres, 2000). Gran parte de estos valores se ha plasmado en la «descentralización», un modelo de reforma educativa que ocupa un lugar central en la agenda de los organismos internacionales para América Latina (Stromquist, 2002).

La descentralización educativa ha sido una de las estrategias que más éxito ha tenido en la región en términos de la cantidad de países que la han implementado, motivados por la promesa de mejorar simultáneamente la eficiencia, la calidad y la equidad de la educación (Hevia, 1991). Sin embargo, la mayoría de estas promesas permanece incumplida. Como observa Carnoy (1999): «Es verdad que la educación parece haber cambiado poco a nivel de las aulas en la mayoría de los países, incluyendo aquellas naciones más involucradas en la economía global y la era de la información. Incluso una de las más importantes reformas educacionales asociada con la globalización, la descentralización de la gestión y del financiamiento educativo, parece tener un impacto escaso o nulo sobre la educación en el aula».

SÍNTESE: A globalização tem transferido ao âmbito do debate educativo um novo repertório de conceitos e de valores econômicos, tais como privatização, produtividade, eficiência, avaliação de rendimento, desregulamentação, participação local na tomada de decisões, competência e liberdade de escolha por parte dos consumidores (Burbules e Torres, 2000). Grande parte destes valores se plasmou na "descentralização», um modelo de reforma educacional que ocupa um lugar central na agenda dos organismos internacionais para a América Latina (Stromquist, 2002).

(*) Investigadora asociada al Centro de Estudios Internacionales, Universidad Torcuato Di Tella, Argentina. 
A descentralização educacional tem sido uma das estratégias de maior êxito na região em termos da quantidade de países que a implementaram, motivados pela promessa de melhorar simultaneamente a eficiência, a qualidade e a eqüidade da educação (Hevia, 1991). No entanto, a maioria destas promessas permanece descumprida. Como observa Carnoy (1999): "É verdade que a educação parece ter mudado pouco em salas de aula na maioria dos países, incluindo aquelas nações mais envolvidas na economia global e na era da informação. Inclusive, uma das mais importantes reformas educacionais associada com a globalização, a descentralização da gestão e do financiamento educativo, parece ter um impacto escasso ou nulo sobre a educação na sala de aula».

\section{INTRODUCCIÓN}

Según un estudio realizado por Schwartzman (2000), la tendencia a una mayor descentralización de los sistemas educativos, acompañada por una mayor autonomía en las escuelas y una mayor participación de la comunidad, es, entre todas las tendencias emergentes, la que mayor optimismo ha suscitado entre los expertos educacionales respecto del futuro de la educación en la región (citado en Brunner, 2001).

Este trabajo pretende ser un aporte a la comprensión del fenómeno de la descentralización educativa, focalizado en las características del diseño y en la implementación de las reformas en Argentina y Chile. El documento está organizado de la siguiente manera: en la primera sección, se hace una reseña de los orígenes de los sistemas educativos en el Cono Sur; la segunda indaga sobre las razones que motivaron la descentralización educativa en Argentina y Chile; la tercera estudia las estrategias de descentralización sobre la base de las funciones, las autoridades y las titularidades que han sido objeto de transferencia desde el gobierno central a las provincias (Argentina) y los municipios (Chile); finalmente, a modo de conclusión, se hacen aportaciones con respecto al rol del Estado en función de las lecciones del pasado y de los desafíos del futuro.

\section{LAS REFORMAS DE FINES DEL SIGLO XX EN ARGENTINA Y CHILE}

En la década de los 80 se implementa en Chile un conjunto de medidas tendientes a transformar el sistema de provisión de servicios 
educativos (oferta), y el funcionamiento del mercado por el cual las familias seleccionan un establecimiento escolar para sus hijos (demanda). Entre 1980 y 1986 se traspasaron las escuelas básicas y los liceos de enseñanza media a los municipios, quedando estos últimos encargados de la infraestructura y el equipamiento, de la administración financiera y de los recursos humanos de las escuelas. Esta municipalización del sistema no se limitó a reformar el gobierno y la gestión educativa, sino también a un proceso de privatización mediante la introducción de mecanismos de mercado por los cuales las familias tienen libertad de elección para la escolaridad de sus hijos en establecimientos municipales/públicos, privados subsidiados o privados.

Paralelo a un gran esfuerzo de ampliación, diversificación y modernización del sistema educativo nacional, éste evolucionó desde un esquema de fuerte y directa responsabilidad estatal en la oferta, ejercida en términos centralizados, a una creciente participación del sector privado y a un replanteamiento del rol del Estado, en un sentido de descentralización y de transferencia de la función de administración de los centros educativos (Núñez y otros, 1994).

La Ley Orgánica Constitucional de Enseñanza, sancionada en 1990, fija los objetivos generales de los ciclos educativos, y establece que los centros educativos podrán proponer sus propios planes y programas de enseñanza de acuerdo con los contenidos básicos definidos por el Ministerio. A partir de esto, y durante los años 90, se produjo una segunda ola de reformas orientada a reforzar la autonomía de los establecimientos educativos, y, simultáneamente, a apuntalar desde el gobierno las iniciativas tendientes a mejorar los resultados del aprendizaje. Entre ellas se destacan la creación de redes y de nuevas oportunidades de desarrollo profesional para docentes, el financiamiento por concurso de proyectos de mejoramiento educativo (PME), los nuevos esquemas de evaluaciones e incentivos de rendimiento por escuela (SIMCE y SNED ${ }^{1}$ ), la creación de un paquete de programas compensatorios, y la extensión de la jornada escolar (Delannoy, 2000).

En Argentina, las primeras experiencias en materia de descentralización se concretan en 1978 con la transferencia de 6.700 escuelas

${ }^{1}$ Programa que provee fondos adicionales a las escuelas que obtienen buenos resultados en las pruebas estandarizadas, en función de una fórmula que combina elementos como valor agregado, equidad de oportunidades, innovación y participación (de Moura Castro y Wolff, 2001). 
primarias nacionales a las provincias ${ }^{2}$. Una década más tarde se sanciona la Ley de Transferencia de los Servicios Educativos a las provincias (1992), por la cual tanto las escuelas secundarias como los establecimientos de educación superior no universitarios pasan a funcionar dentro de las jurisdicciones provinciales: 3.578 escuelas secundarias nacionales (incluyendo las escuelas técnicas y las privadas con subsidio) pasan a las provincias. A partir de la sanción de la Ley Federal de Educación ${ }^{3}$ (1993), el sistema educativo cuenta con un nuevo marco general que regula los servicios educativos en estas jurisdicciones.

\section{LAS RAZONES DE LA DESCENTRALIZACIÓN EDUCATIVA EN ARGENTINA Y CHILE}

\subsection{CONSIDERACIONES PRELIMINARES RESPECTO A LA RELACIÓN ENTRE SISTEMA POLIITICO Y DESCENTRALIZACIÓN EDUCATIVA}

El ordenamiento del sistema político en unitario o en federal influye en la estructuración de los sistemas educativos nacionales. Mientras que un Estado unitario tiene competencias en un territorio delimitado por las fronteras del país, en el federal coexisten las áreas de competencia del Estado federal y las de los estados que lo componen.

Argentina es un Estado federal. Su organización política está compuesta por el gobierno nacional y por los gobiernos provinciales. Las bases legales que rigen la educación nacional están determinadas en la Constitución del país y en las provinciales, en las leyes nacionales y provinciales, y en los decretos y resoluciones de uno u otro.

Por un lado, la Constitución Nacional Argentina norma el derecho a la educación: el art. 14 garantiza el derecho a enseñar y aprender,

${ }^{2}$ En el período 1970-77 el Estado disponía de más de un tercio del gasto público total destinado a la educación básica, y en el período 1978-85 sólo ejecutaba el 7\% del mismo, en tanto que las provincias y la Municipalidad de la Ciudad de Buenos Aires ejecutaban el $93 \%$ restante. Cabe aclarar que, dado el esquema de coparticipación federal, esto no implicó una reducción proporcional de la participación del Estado en materia de financiamiento de la educación básica (Repetto y otros, 2001).

${ }^{3}$ Hasta 1993, el sistema educativo se estructuraba en cuatro niveles: Inicial, Primario, Medio y Superior, donde el Primario era obligatorio. A partir de la sanción de la Ley Federal de Educación se mantiene el nivel inicial (cuyo último año pasa a ser obligatorio), y se define una Educación General Básica (obligatoria y de nueve años de duración), seguida por el nivel Polimodal (tres años de duración). 
y, por otro, en función del principio de organización federal del Estado, el art. 5 establece que «cada provincia dictará para sí una Constitución bajo el sistema representativo y republicano, de acuerdo con los principios, derechos y garantías de la Constitución Nacional, y que asegure [...] la educación primaria». El Estado Federal, las provincias, los municipios y los agentes del sector privado, están concurrentemente involucrados en la prestación de servicios educativos.

A pesar de la centralización normativa y estructural de la educación, vigente hasta principios de la década de los 90, la falta de articulación y de coordinación entre un número elevado de actores contribuyó a una notable atomización del sistema educativo (Repetto y otros, 2001). Por ser Argentina un Estado federal, la educación se ubica en una zona gris, en la que tanto el Estado como las provincias tienen competencias y facultades concurrentes (de Senén González, 1994).

Por ejemplo, la coexistencia de escuelas primarias nacionales y provinciales hasta la reforma de 1978 es un caso claro de duplicación de estructuras. Como señala Tedesco (1992), este efecto es típico de los países federales, y se observa en los casos de descentralización parcial del sistema.

No sólo en el plano normativo y estructural sino en la práctica, el caso argentino revela la compleja dinámica del sistema federal, tanto por el rechazo a la transferencia de escuelas primarias manifestado por algunas provincias durante la década de los 70, como por el apoyo declarado después por el Congreso Pedagógico Nacional, en el que se reivindicó «un conjunto de reclamos en pos de un verdadero federalismo y mayor autonomía de las provincias frente a un poder que respondía principalmente a los sectores económicos vinculados con el proyecto agroexportador centrado en el puerto de Buenos Aires» (Filmus, 1997).

A diferencia de Argentina, Chile, de acuerdo con el art. 3 de la Carta Fundamental, «es unitario [...] y su territorio se divide en regiones. La ley propenderá a que su administración sea funcional y territorialmente descentralizada».

\subsection{LÓGICA POLIITICA, ORIENTACIÓN, NECESIDADES Y OBJETIVOS DE LA DESCENTRALIZACIÓN}

Para comprender los orígenes de los procesos de descentralización educativa en Argentina y Chile desde una perspectiva comparada, 
es necesario distinguir las diferentes causas que motivan su implementación. Este capítulo propone analizar los factores explicativos de las reformas en función de las siguientes dimensiones: lógica-política (Filmus, 1997); orientación (Burki y otros, 1999); necesidades (Carnoy, 1999); y objetivos (Hanson, 1997).

\section{a) Lógica-política}

Los procesos fundamentados sobre una lógica pedagógica conciben la descentralización como un mecanismo de mejora de la calidad. Cuando las que prevalecen son la economicista (enfocada a optimizar la administración fiscal del Estado a través del ahorro del gasto público) o la tecnocrática (dirigida a mejorar la eficiencia de la gestión, es decir, la relación entre gasto y rendimiento), la descentralización tiene por objetivos el mejoramiento del bienestar social y la eficiencia técnica. En la lógica economicista-tecnocrática, la toma de decisiones y la asignación de recursos asociados son, en principio, más eficientes cuando están en manos de quienes tienen información específica sobre la realidad local (necesidades de los alumnos, precio/calidad de los insumos, función de producción, etc.). A diferencia del planteo anterior, la lógica democrático-participativa promueve la transferencia de las decisiones y la asignación de recursos a los administradores escolares, a los docentes, a los padres y a otros actores de la comunidad educativa local, pero ya no por criterios eficientistas sino por las nociones de compromiso comunitario y de participación ciudadana (Filmus, 1997). Con la delegación del planeamiento, la toma de decisiones y el control en la comunidad local obtendrían mejores resultados tanto desde el punto de vista de la eficiencia (relación entre gasto y rendimiento) como de la eficacia (cumplimiento de objetivos) del sistema educativo (Burki y otros, 1999; Carnoy, 1999).

\section{b) Orientación hacia la estructura vs. orientación hacia los contenidos}

Burki y otros (1999) enfatizan la orientación de la descentralización hacia cambios en la estructura y/o los contenidos de la educación, y señalan que estos dos tipos de reforma reconocen distintos orígenes y objetivos. La descentralización de la educación puede realizarse en el marco de una reforma estructural general de la administración pública con objetivos técnicos o políticos, y/o surgir como respuesta a la 
necesidad de mejorar la calidad de la educación. Cuando el objetivo es otorgar mayor control a nivel local, ya sea por razones técnicas o políticas, se trata de una reforma estructural, mientras que cuando la reforma enfatiza aspectos curriculares y pedagógicos con el objetivo de mejorar la calidad de la educación, se trata de una reforma de contenido.

\section{c) Reformas como respuesta a necesidades de competitividad, financieras o de equidad}

En esta misma línea argumental, Carnoy (1999) distingue tres tipos de motivaciones básicas para emprender reformas: las justificadas por la necesidad de competitividad (competitiveness-driven), las fundadas en razones financieras (finance-driven), y las causadas por la necesidad de lograr una mayor equidad social (equity-driven). Por un lado, las reformas motivadas por la necesidad de competitividad apuntan a mejorar la productividad de las instituciones a través de una mejor administración de los recursos tecnológicos, financieros, físicos y humanos, y a garantizar un mejor funcionamiento del mercado. Por otro, las reformas en las instituciones públicas promovidas por razones financieras están relacionadas con la reducción del gasto público. Finalmente, las originadas en el concepto de equidad suponen que la igualdad de oportunidades es una condición necesaria para promover la movilidad social, sobre todo en los grupos socioeconómicos más desfavorecidos.

\section{d) Los objetivos de la descentralización educativa en Argentina y Chile}

En Argentina, la transferencia de las escuelas primarias (1978) y de las escuelas secundarias (1992) a las provincias consiste en una medida economicista de ajuste estructural, que traslada la responsabilidad del gasto público en educación a las provincias con el propósito de mejorar el equilibrio fiscal de las cuentas nacionales ${ }^{4}$ (Hanson, 1999).

Filmus (1997) destaca que «los factores fiscales cobraron preponderancia frente a la necesidad de repensar globalmente el nuevo

${ }^{4}$ La transferencia de las escuelas secundarias a las provincias fue uno de los compromisos adoptados por el Gobierno nacional ante el Fondo Monetario Internacional durante las negociaciones para la refinanciación de la deuda externa (1989-1991) (de Senén González y Arango, citado en Gorostiaga y otros, 2003). 
tipo de articulación entre el Estado y la sociedad que debía surgir a partir de la crisis del tipo de Estado vigente». En este sentido, la transferencia de la responsabilidad educativa a las provincias puede ser considerada como una estrategia economicista y como un instrumento tecnocrático de la planificación nacional que compromete a todas las instituciones del Estado, puesto que la acción educativa se integra con la descentralización administrativa de los servicios públicos en general (Latorre y otros, 1991; Hevia, 1991).

La calidad de la educación es el eje de todo discurso que intente avalar una reforma significativa en educación. Sin embargo, el hecho de que la reforma en Argentina esté regida por una lógica política economicista y tecnocrática, hace que, en la práctica, el mejoramiento de los aspectos pedagógico-curriculares sea sólo un potencial efecto secundario derivado de una mayor eficiencia administrativa del sistema.

La primera ola de reformas tendientes a la descentralización del sistema educativo chileno (década de los 80 ) es comparable al caso argentino desde el punto de vista de los factores que la motivaron, dado que la lógica política subyacente al plan chileno es economicista y tecnocrática. No obstante, la reforma chilena no se limitó a la necesidad de racionalizar recursos escasos, sino a facilitar el control local y la evaluación de la eficiencia de los establecimientos educativos; a promover la competencia por alumnos entre escuelas; y a permitir la libertad de elección de escuelas por parte de las familias ${ }^{5}$ (Schiefelbein y Schiefelbein, 2000).

La reforma estructural implementada en Chile durante la década de los 80 se organizó alrededor de la municipalización de las escuelas y de la privatización del sistema, motivo por el cual es posible designar esta iniciativa en términos de una «descentralización con orientación privatizadora» (UNESCO, 2001).

Por un lado, la descentralización consistió en transferir a los más de 300 municipios del país una serie de competencias administra-

${ }^{5}$ Los cambios estructurales y legales impulsados por el gobierno militar estuvieron orientados a la promoción de una economía de libre mercado y al debilitamiento del rol del Estado en la provisión de servicios públicos; por esa razón, quienes diseñaron e implementaron la reforma fueron apodados «Chicago boys» (Schielfelbein y Schiefelbein, 2000), y el modelo imperante en la década de los 80 recibió la denominación de «Chicago economics» (Delannoy, 2000). 
tivas relacionadas con la infraestructura y el equipamiento, y con la gestión de recursos financieros y hum anos ${ }^{6}$. Este cambio radical consistió en separar el financiamiento de la provisión de los servicios educativos. Mientras el financiamiento continúa a cargo del Estado, a partir de la reforma son los municipios quienes deben atender todos los aspectos de la gestión educativa.

Por el otro, se modificó el mercado tanto en la demanda como en la oferta de servicios educativos. Desde el punto de vista de la demanda, se promovió la libertad de elección de los padres con respecto a la institución escolar para la educación de sus hijos, con independencia de su ubicación geográfica y de todo otro factor exógeno a su criterio. Asimismo, en el plano de la oferta de servicios educativos se promovió la libre competencia entre escuelas públicas y privadas, lo que significó en la práctica la privatización de la educación. La principal herramienta de promoción de la actividad privada en educación consistió en un esquema que combinó dos nuevas herramientas de financiamiento del sistema: la distribución de subsidios en proporción a la cantidad de alumnos matriculados tanto en escuelas municipales como en escuelas privadas; y un plan de incentivos para involucrar a empresas y a corporaciones en la administración de escuelas técnicas y vocacionales. Muchos autores utilizan el término privatización para designar esta estrategia de financiamiento por el peso relativo de la actividad privada en el mercado educativo ${ }^{7}$.

En conclusión, a pesar de que tanto en Chile (década de los 80) como en Argentina (década de los 90) se implementaron reformas estructurales fundadas en una lógica política economicista ${ }^{8}$ y tecnocrática, la estrategia chilena de reforma educativa combinó la gestión local (municipal) de las escuelas con un esquema de subsidios per cápita para

${ }^{6}$ Los docentes fueron transferidos a los municipios con el estatus jurídico de trabajadores del sector privado. Así, la negociación de los salarios debía tener lugar en cada uno de los más de 300 municipios, lo que implicaba una disolución del poder de negociación del sindicato, que ya no podía imponerse en un proceso de negociación colectiva a nivel nacional (Casassus, 2000; Schiefelbein y Schiefelbein, 2000).

7 Durante la primera década de la experiencia, la matrícula en escuelas primarias privadas se duplicó como consecuencia del sistema de subsidios per cápita. Además, la cantidad de escuelas privadas pasó de 1.700 a 2.700 en sólo seis años.

${ }^{8}$ Cabe destacar que, si bien la reducción del gasto público en educación no fue un objetivo inicial de la reforma chilena debido a la crisis fiscal y a políticas posteriores a su implementación, el gasto total en educación se redujo drásticamente durante la década de los 80 (Delannoy, 2000). 
escuelas públicas y privadas, lo que la diferencia de la Argentina y constituye un experimento único en la región y en el mundo.

Como balance general de la experiencia de descentralización educativa implementada en Chile durante la década de los 80, Carnoy (1999) concluye:

La experiencia con esta versión de descentralización inspirada por necesidades financieras sugiere fuertemente que la descentralización con una desaceleración o una reducción de asistencia técnica y financiera desde el gobierno central hacia el gobierno local puede alcanzar los objetivos financieros, pero tiende a incrementar la inequidad entre los resultados educativos de los estados (municipios) pobres y los de los estados ricos.

Con el retorno a la democracia (1990), Chile inició una segunda ola de reformas en su sistema educativo. Los magros resultados de aprendizaje de los alumnos y la agudización de la desigualdad en la distribución social de las oportunidades educativas (Latorre y otros, 1991; PIIE, 1991; Hanson, 1997; Carnoy, 1999; Edwards y Henales, 2000), motivó una reforma, que, a diferencia de la de los 80 , se centró en los aspectos estructurales del sistema y en los contenidos. En la última década del siglo XX prevaleció la lógica pedagógica (orientada al contenido de los aspectos pedagógicos y curriculares de la educación) y una concepción democrático-participativa que promovió el acceso de todos los ciudadanos a una educación de calidad (equidad). Al respecto, Castro Silva (1993) observa:

La descentralización administrativa de la enseñanza responde a exigencias propias de la racionalidad instrumental, es decir, a una racionalidad que se agota en la mera coordinación de medios para alcanzar, con economía de tiempo, de fuerzas y de recursos, objetivos prácticos mensurables [...]. La descentralización curricular, en cambio, se encuentra animada por una lógica de carácter más bien político, por una lógica de la participación social.

En la década de los 90 Chile mantiene la descentralización administrativa y financiera implementada en la década anterior, y la complementa con una delegación parcial de las decisiones pedagógicas y curriculares y con la promoción del microplaneamiento educativo en el

\footnotetext{
${ }^{9}$ Según concluye Delannoy (2000), tanto por su duración como por su escala, la reforma estructural del sistema educativo chileno en la década de los 80 constituye el mayor ensayo de un sistema de vouchers en el mundo.
} 
ámbito de la escuela. Asimismo, se realizan intervenciones focalizadas a través de programas compensatorios para las poblaciones más vulnerables (porejem plo: MECE Rural para establecimientos situados en zonas de baja densidad poblacional; Programa P-900 para escuelas con alumnado de bajo nivel socioeconómico, entre otros).

La lógica subyacente a la descentralización es tanto política como educativa, y, por consiguiente, la mayoría de las reformas es una combinación de estructura y de contenido (Burki y otros, 1999; McGinn y Welsh, 1999). Igualmente, las motivaciones que rigen las sucesivas reformas pueden evolucionar a lo largo del tiempo, tal como demuestra el caso de Chile, donde la descentralización se implementa en función de una política de ajuste estructural, para luego evolucionar hacia un modelo de descentralización pedagógico-curricular orientado a mejorar la calidad educativa, con intervención del Estado mediante programas de discriminación positiva que promuevan la equidad.

\section{ESTRATEGIAS DE LA DESCENTRALIZACIÓN EDUCATIVA}

El análisis comparado de la descentralización en Argentina y Chile permite detectar un patrón en el cual los procesos de descentralización no son independientes de los de centralización (Casassus, 2000).

Estos procesos resultan, a priori, conceptualmente contradictorios y empíricamente incompatibles. El propósito de este capítulo es analizar cómo y porqué se producen procesos simultáneos de descentralización y centralización educativa durante las reformas implementadas en Argentina y Chile a fines del siglo XX. Para ello, el capítulo se organiza en función de tres grados de transferencia de la autoridad dentro del sistema educativo: desconcentración, delegación y devolución.

La desconcentración se produce mediante la transferencia de tareas y de responsabilidades, pero no de autoridad, hacia otras unidades del sistema. La delegación es un proceso por el cual se transfiere la autoridad para tomar decisiones a unidades de más bajo nivel dentro de la jerarquía. Sin embargo, esa autoridad puede ser removida si así lo considera la unidad que delega. Las organizaciones delegadas tienen autoridad semiindependiente para ejecutar las tareas que se les han encomendado (Di Gropello, 1993). Finalmente, la devolución consiste 
en una transferencia de autoridad a una unidad que puede actuar de manera independiente ${ }^{10}$.

A continuación se analizan las estrategias de descentralización implementadas en Argentina y Chile según competencias administrativas, pedagógico-curriculares y de evaluación de rendimiento.

\section{ARGENTINA}

En Argentina, antes de la reforma de 1992/93 la gestión de la educación media y del nivel superior no universitario estaba centralizada, y las funciones del Ministerio de Educación Nacional estaban desconcentradas en los ministerios de educación provinciales. A partir de la sanción de la Ley de Transferencia de los Servicios Educativos a las provincias (1992), las funciones administrativas del Ministerio de Educación consisten en favorecer una adecuada descentralización de los servicios educativos; en desarrollar programas de asistencia y cooperación técnica; en promover y organizar la formación y actualización docente; y en administrar programas compensatorios.

De forma complementaria, la Ley Federal de Educación establece las siguientes competencias administrativas para las provincias: planificar, organizar y administrar el sistema educativo de su jurisdicción; organizar y conducir los servicios educativos de gestión estatal, y autorizar y supervisar los establecimientos de gestión privada de su jurisdicción; aplicar las decisiones del Consejo Federal de Cultura y Educación con las correspondientes adecuaciones; promover la participación de las organizaciones integradas por los trabajadores de la educación en el mejoramiento de la calidad de ésta con aportes técnicopedagógicos que perfeccionen la práctica educativa, así como la de los demás miembros de la comunidad educativa. De esta forma, cada ministerio provincial ha recibido las mismas funciones que fueron ejercidas por el Ministerio de Educación Nacional, lo que es caracterizado por McGinn y Welsh (1999) como una «descentralización territorial».

${ }^{10}$ Aunque McGinn y Welsh (1999), basados en el trabajo de Rondinelli y otros., agregan la privatización como un cuarto grado de transferencia de la autoridad, la mayoría de los autores coincide en considerar la privatización como una forma particular de devolución. 
Sin embargo, dada la organización política de la Argentina, los fondos para el financiamiento del sistema proceden no sólo de la recaudación tributaria de las provincias, sino del esquema de coparticipación federal por el cual el Estado transfiere fondos propios a las provincias. Después de la descentralización estipulada por ley, este financiamiento conjunto implica que el Estado y las provincias son solidariamente responsables y garantes de la educación pública gratuita, a través de la provisión de las partidas presupuestarias necesarias. Por eso, el proceso de transferencia de las escuelas medias a las provincias es, en realidad, «una desconcentración», puesto que el Ministerio Nacional transfiere competencias administrativas a los ministerios provinciales, pero éstos mantienen una relación de dependencia económico-financiera con respecto al gobierno central ${ }^{11}$. La descentralización territorial a la que hacen referencia McGinn y Welsh implicaría la «delegación de facultades operativas y el ejercicio de un poder de decisión real [mientras que la desconcentración se produce cuando] la delegación de funciones se hace a organismos que no son autónomos sino que están bajo la dependencia directa del poder central» (Hevia, 1991).

El reconocimiento de los nuevos mecanismos de intervención educativa federal derivados del poder financiero y técnico-diferencial del Estado ${ }^{12}$ justifica la aplicación del concepto de «desconcentración» en la gestión administrativa. Nosiglia y Trippano (2000) defienden la mayor «concentración» de poder en el Estado por su diferencial acceso a recursos técnicos y económicos:

[EI Ministerio de Educación] con capacidad de financiar investigaciones y de contratar los mejores expertos sobre las diferentes temáticas producen acciones de política educativa de carácter nacional, que se legitiman en el Consejo Federal de Educación [...]. Los gobiernos provinciales [...] adoptaron las diferentes propuestas elaboradas por el Poder Ejecutivo Nacional, pues en la

11 Esta dependencia económico-financiera es evidente sobre todo en las provincias donde predomina una población de bajo estatus socioeconómico, por la importancia insoslayable de los programas compensatorios financiados por el Estado.

${ }^{12} \mathrm{~A}$ efectos de instrumentalizar la Ley Federal de Educación, el Estado, a través del Ministerio de Educación, ha desarrollado y financiado distintos programas (Plan Social Educativo, Programa Nueva Escuela, Programa Nacional de Becas Estudiantiles, Programa de Formación y Capacitación para el Sector Educación, etc.) que se caracterizan por promover acciones como asistencia técnica en terreno, contratación de expertos y consultores, otorgamiento de becas y subsidios, realización de transferencias directas a las escuelas, entre otras (Repetto y otros, 2001). 
mayoría de los casos implicaba nuevos recursos para sus sistemas educativos.

La dependencia de las provincias con respecto a los recursos técnicos y financieros implica una estrategia de desconcentración. Pero en lo concerniente a los demás aspectos de la gestión administrativa se trata de una devolución a las provincias, puesto que la organización y la conducción de las escuelas públicas, incluyendo las decisiones relativas a la obtención y administración de recursos financieros, el reclutamiento y la contratación de personal docente, la determinación del régimen salarial y la capacitación, son competencias exclusivas del gobierno provincial.

Por tal razón, cuando se combina un nivel central que sigue financiando una parte importante de la educación con niveles subnacionales que detentan un alto grado de autonomía en la asignación de estos recursos y en el ejercicio de las demás funciones asociadas a la provisión de los servicios educativos, se trata de una «devolución híbrida» (Di Gropello, 1999).

Es conveniente observar que en cada uno de los 24 subsistemas educativos la toma de decisiones se encuentra muy centralizada, puesto que las escuelas no tienen ninguna injerencia en los aspectos administrativos y económico-financieros de la gestión educativa. No se observa en los establecimientos educativos el desarrollo de prácticas de planificación, de gestión y evaluación, ni la capacidad de aprendizaje organizacional, la oportunidad de asignar recursos para financiar actividades no rutinarias, o la toma de decisiones relevantes sobre gestión del personal docente (Decibe, 2003).

En Argentina, los aspectos curriculares de la gestión educativa están normados por la Ley de Transferencia de los Servicios Educativos a las provincias y por la Ley Federal de Educación, las cuales determinan las competencias fundamentales del Ministerio de Educación: el establecimiento de los contenidos básicos comunes, y el dictado de normas sobre equivalencia de títulos y de estudios.

En 1992 se creó el Consejo Federal de Educación para facilitar la descentralización del sistema educativo ${ }^{13}$. El hecho de que el Consejo

${ }^{13}$ EI Consejo está compuesto por todos los ministerios de educación provinciales y por el Ministerio Nacional, que lo preside, y está a cargo de la definición de los principales lineamientos de la política educativa del país. 
se desempeñe como un órgano de coordinación y de concertación de intereses provinciales que carece de facultades para decidir y para establecer la normativa (sin concertación previa) sobre la acción educacional de las provincias (Castro Silva, 1993), implica que no se trata de una transferencia de la autoridad curricular desde el ex Consejo Nacional de Educación hacia el nuevo Consejo Federal, sino de una devolución indirecta de la autoridad curricular a las provincias ${ }^{14}$. Además, la Ley Federal de Educación establece que los equipos técnicos de los ministerios provinciales están a cargo de la elaboración de los diseños curriculares por nivel y por regímenes especiales que se implementen en su jurisdicción, con lo cual, por la normativa legal y por la propia dinámica del Consejo Federal, las provincias han recibido una gran autonomía en materia curricular.

De acuerdo con los términos propuestos por Manuel de Puelles Benítez (1993), este modelo de descentralización federal se caracteriza por com binar una descentralización por amba con una centralización por abajo. Según él, «los entes temitoriales que han visto reconocer su condición estatal en la Constitución Federal han conseguido tam bién que se les atribuya la educación prácticam ente en exchusiva. Pero, por otra parte, son países en los que la educación aparece centralizada en los Estados $m$ iem bros, sin que las dem ás com unidades territoriales tengan un papel im portante en los asuntos educativoss».

En este sentido, cabe aclararque las escuelas han obtenido una m ayor libertad en cuanto al diseño de m etodologías de enseñanza, a oferta de estudios electivos, a selección de $m$ ateriales didácticos, a organización de las nutinas y de las aulas, etc. Asm ism o, cada escuela puede producirsu propio Proyecto Educativo Institucional: se trata de un proceso participativo porelcuallos docentes y los directivos de la escuela definen conjuntam ente la estructura adm inistrativa de la institución, y que especifica el curriculo del establecim iento de acuerdo con los lineam ientos generales establecidos por la provincia. Sin em bargo, la descentralización dentro de las provincias mediante una desconcentración intrajunsdiccionalde funciones relativas aldiseño curricular,

${ }^{14}$ Con respecto a la concertación de la política educativa entre provincias, y en línea con la idea de dependencia económica de éstas con respecto al gobierno central, Decibe (2003) señala: «Hasta ahora, en la mayoría de los casos los acuerdos federales de política educativa han terminado basándose sólo en los recursos que se obtienen o no a partir de ellos, dado que no existen instrumentos que obliguen a las partes a su cumplimiento». 
ha sido esencialmente retórica (Experton, 1999, citado en Gorostiaga y otros, 2003).

En Argentina, la evaluación del sistema educativo nacional es tanto una competencia del Estado como de las provincias. Por un lado, el Ministerio de Educación evalúa el funcionamiento del sistema educativo en todas las jurisdicciones, niveles, ciclos y regímenes, a los efectos de garantizar el cumplimiento de los principios, objetivos y funciones del Sistema Nacional de Educación, conforme a lo establecido en la Ley de Transferencia de los Servicios Educativos a las provincias. Por otro, cada una de las jurisdicciones provinciales debe evaluar periódicamente el sistema educativo en el ámbito de su competencia, controlando su adecuación a las necesidades de su comunidad, a la política educativa nacional y a las políticas y acciones concertadas en el seno del Consejo Federal de Cultura y Educación. En tal sentido, los ministerios provinciales funcionan como órganos desconcentrados del Ministerio Federal, puesto que reciben competencias funcionales relacionadas con los procesos de evaluación, pero las competencias normativas permanecen en el ámbito del gobierno nacional.

\section{CHILE}

En Chile, por regla general los ministerios son órganos normativos y supervisores que se desconcentran por la transferencia de tareas y de responsabilidades - pero no de autoridad- a sus representaciones regionales. Conforme a esto, y con anterioridad a la reforma de 19801986, el Ministerio de Educación opera en tres niveles: nacional, regional y municipal. Se desconcentra funcional y territorialmente en 13 Secretarías Regionales Ministeriales, cuyas competencias administrativas consisten en planificar, normar y supervisar el desarrollo del proceso educativo en los establecimientos ubicados en su territorio, velando por el cumplimiento de los objetivos y de las políticas educacionales y por su correcta adecuación a las necesidades y a los intereses regionales.

A partir de la municipalización del sistema educativo se produce una devolución de control a los municipios, puesto que el control sobre gran parte de la gestión adm inistrativa les fue cedido ${ }^{15}$. Además de

${ }^{15}$ Cabe destacar que esta devolución no supuso una gestión democráticoparticipativa a nivel local durante el régimen dictatorial, porque, entre otros factores, los alcaldes eran designados por el gobierno central. 
implementar los lineamientos generales de política educativa fijados por el Ministerio, los municipios determinan la apertura y el cierre de escuelas públicas, su estructura administrativa, el planeamiento y la administración del presupuesto escolar ${ }^{16}$, y la contratación, la remuneración y la capacitación de los docentes (Burki y otros, 1999; Casassus, 2000; Hanson, 1997; Narodowski y Nores, 2002).

Asimismo, la creciente privatización del sistema educativo significó una devolución al sector privado por la transferencia de recursos desde el sector público, a través de un esquem a de vouchers a la demanda y de incentivos para la gestión corporativa de escuelas técnicovocacionales.

Las funciones del Ministerio de Educación (1990) quedan limitadas a las siguientes funciones y competencias: proposición y evaluación de las políticas educacionales y culturales, estudio y propuesta de las normas generales del sector, asignación de los recursos necesarios para el desarrollo de actividades educacionales y de extensión cultural, y otorgamiento de reconocimiento oficial a los establecimientos educacionales.

Sin embargo, cabe destacar que, al igual que en Argentina, tanto la municipalización como la privatización de los servicios educativos se ven parcialmente debilitadas por la dependencia económicofinanciera respecto del gobierno central. Como señala Decibe (2003), «la iniciativa local se ve significativamente reducida cuando el financiamiento total de la educación depende del presupuesto del gobierno central». En consecuencia, la descentralización en ambos países revela una estrategia de devolución híbrida de autoridad, de competencias y de titularidad en el área de gestión administrativa.

La Ley Orgánica Constitucional de Enseñanza dictada en 1990, establece que el Ministerio de Educación define los objetivos fundamentales y los contenidos básicos de los estudios en los niveles de enseñanza básica y media, en función de los cuales las escuelas pueden definir su propio plan y programa de estudio.

${ }^{16}$ Desde 1997 las escuelas reciben fondos para implementar planes de mejora escolar sobre los cuales tienen total autonomía. Sin embargo, como señala Delannoy (2000), el hecho de que el Ministerio organice los concursos y establezca las reglas del juego por las cuales se seleccionan proyectos para su financiamiento, determina que el control sobre las innovaciones escolares siga siendo centralizado. 
No obstante, antes de su implementación, las escuelas deben contar con un informe favorable por parte del Consejo Superior de Educación, que posee atribuciones superiores a las del Ministerio de Educación en materia curricular. En ese sentido, y desde el punto de vista pedagógico-curricular, no existe una devolución de la autoridad curricular a las escuelas, sino una desconcentración de la responsabilidad curricular (transferencia de las responsabilidades y de las tareas relacionadas con el diseño curricular del plan y programa de estudios, pero no de autoridad) desde el Ministerio de Educación a las escuelas, y una devolución de la autoridad curricular desde ese Ministerio al Consejo Superior de Educación (organismo nacional-central), que puede actuar de manera independiente.

El Ministerio de Educación realiza actividades sistemáticas de evaluación de las políticas y de los planes educativos, y comparte la responsabilidad de la supervisión técnico-pedagógica con las 13 Secretarías Regionales Ministeriales que funcionan como organismos desconcentrados del Ministerio.

El análisis comparado de las estrategias de descentralización en Argentina y Chile, permite sacar las siguientes conclusiones:

- Tanto en Argentina como en Chile, la definición de la política educativa del país sigue siendo la función primordial del Ministerio de Educación Nacional.

- En el caso argentino, antes de la transferencia el gobierno nacional y las provincias financiaban los establecimientos educativos que estaban bajo sus respectivas dependencias. Después, las provincias ejecutan el presupuesto para todos los establecimientos ubicados en su territorio, pero el Estado mantiene una importante participación como fuente de financiamiento en función del esquema de coparticipación federal.

- En Chile no existe una transferencia de titularidad en materia de financiamiento. El Estado sigue siendo la fuente de financiamiento de todos los establecimientos públicos y privados subsidiados.

- La gestión administrativa de la educación ha sido transferida a nivel local en Chile, y regional en Argentina. 
- En ambos casos, los niveles subnacionales mantienen dependencia financiera en relación con el nivel central (en particular con respecto a los programas compensatorios y de asistencia técnica).

- El amplio margen de autonomía regional y/o local en la asignación de recursos financieros procedentes del nivel central, puede ser caracterizada como devolución híbrida.

- En ambos países el Ministerio se reserva la autoridad máxima en materia curricular, ejercida mediante la definición de los contenidos básicos por nivel.

- La gestión pedagógico-curricular ha sido transferida a nivel interno del establecimiento educativo en Chile, y a los equipos técnicos de los ministerios provinciales en el caso de Argentina.

- La adopción de materiales didácticos y de métodos pedagógicos está relacionada con la definición curricular. Por eso, el tipo de transferencia de estas competencias constituye en ambos casos una desconcentración.

En principio, la idea subyacente a la descentralización educativa es otorgar mayor autonomía en la toma de decisiones por parte de las escuelas y de las comunidades locales a las que pertenecen, con el fin de lograr una mayor compatibilidad entre la oferta de la escuela y las necesidades de los alumnos, y, a la vez, aumentar la responsabilidad de la escuela sobre los resultados educativos. Sin embargo, a diferencia del caso chileno, sobre todo a partir de la estrategia de la década de los 90, más orientada a afectar la realidad del aula a través de iniciativas como PME, SIMCE y SNED, en Argentina la devolución de gran parte de la autoridad administrativa y curricular fue una transferencia desde el nivel central hacia el nivel regional/provincial, lo que no garantizó la participación de los actores locales en el proceso. Por el contrario, la descentralización del sistema educativo nacional significó una mayor centralización de las provincias en materia educativa (de Senén Gonález, 1989, citado en Filmus, 1997; Nosiglia y Trippano, 2000; Decibe, 2003).

A juzgar por las experiencias de reforma en Argentina (década de los 90) y de Chile (década de los 80), el hecho de que la descentralización esté regida por una lógica economicista y tecnocrática orientada a satisfacer necesidades financieras mediante ajustes estructurales, 
hace que la descentralización sea impuesta verticalmente por los gobiernos nacionales, y que consista en una devolución a las provincias y a los municipios (respectivamente) de la gestión administrativo-financiera, y, en menor medida, de la gestión pedagógico-curricular sujeta a una consistente dependencia de la asistencia técnica y financiera provista por el Estado.

En cuanto a los resultados de las reformas educativas, en el caso chileno no se observan mejoras en lo referente a la distribución de las oportunidades educativas (equidad), a la eficiencia de la administración pública, a los niveles de aprendizaje de los alumnos, ni a la participación de los actores de la comunidad local (Carnoy, 1999; Delannoy, 2000; Edwards y Henales, 2000; Hanson, 1997; Latorre y otros, 1991; Hevia, 1991; PIIE, 1991; Schiefelbien y Schiefelbein, 2000). De forma similar, el peso de la lógica tecnocrático-economicista subyacente a la reforma educativa en Argentina también puede aportar una explicación a la hora de interpretar las limitaciones en cuando a mejoras en la participación, la calidad, la equidad y la eficiencia del sistema (Filmus, 1997, Decibe, 2003).

Por eso, en ambos países se observa una mayor intervención del gobierno central a nivel local a través del ejercicio centralizado de nuevas funciones tendientes a mejorar la calidad y la equidad de la educación. A pesar de los grandes cambios políticos, económicos y sociales del siglo XX, de la creciente influencia de los organismos internacionales en la definición de políticas públicas domésticas, y del siempre presente debate sobre los roles del Estado y del mercado en la provisión de bienes y servicios públicos, las experiencias argentina y chilena en materia de reforma educativa demuestran que la descentralización absoluta de la educación no es ni posible ni deseable, y que el Estado debe redefinir sus funciones sin descuidar el fin de integración social que le dio origen.

\section{BIBLIOGRAFÍA}

BRAY, M. (1999): «Control of Education: Issues and Tensions», en Robert Arnove y Carlos Torres (eds.), Comparative Education: Dialectic of the Global and the Local, Boston, MA, Rowman y Littlefield.

BRUNNER, J. J. (2001): Globalización y el futuro de la educación: tendencias, desafíos, estrategias. Presentado en el Séptimo encuentro del Comité Regional 
Intergubernamental del Proyecto de Educación en América Latina y el Caribe organizado por UNESCO, Santiago de Chile, agosto, 2000, pp. 23-25.

BURBULES, N. C. y TORRES, C. A. (2000): Globalization and Education, Nueva York, Routledge.

Burki, S. J.; Perry, G. y Dillinger W. (1999): Decentralizing the State, Washington D.C., The Word Bank.

CASASSUS, J. (1990): «Descentralización y desconcentración de los sistemas educativos en América Latina: Fundamentos y dimensiones críticas», en Proyecto Principal de Educación en América Latina y el Caribe, 22, Santiago, Chile, OREALC.

- (2000). La Reforma educativa en América Latina en un contexto de globalización, París, UNESCO.

CARnoy, M. (1999): «Globalization and Educational Reform: what Planners need to know», en Fundamentals of Educational Planning, París, UNESCO-International Institute for Educational Planning.

CASTRO SILVA, E. (1993): «Riesgos y promesas del currículo de colaboración en contextos de descentralización educativa», en Revista Iberoamericana de Educación, núm. 3, Madrid, OEI.

DECIBE, S. (2003): «Educación básica: las reformas pendientes», en Revista Iberoamericana de Educación, núm 31, Madrid, OEI.

Delannoy, F. (2000): «Education Reforms in Chile, 1980-98: A Lesson in Pragmatism», en The Education Reform and Management Publication Series I, (1), Washington D.C, World Bank, Human Development Network.

EdWARDS, B. y HeNALES, L. (2000): «Neoliberalism and Educational Reform in Latin America», en Current Issues in Comparative Education, 2 (2), Nueva York, Teachers College, Columbia University.

FILMUS, D. (1997): «La descentralización educativa en Argentina: elementos para el análisis de un proceso abierto», en Coloquio Regional sobre Descentralización de la Educación en América Central, Cuba y República Dominicana, nov. 3-5, San José, Costa Rica, CLAD.

GorostiagA, J.; ACEDO, C. y CIFRA, S. (2003): «Secondary Education in Argentina During the 1990s: The Limits of a Comprehensive Reform Effort», en Education Policy Analysis Archives, 11 (17).

GROPELLO, E. di (1999): «Los modelos de descentralización educativa en Am éricaIatina», enRevista de la CEPAL, 68, Santiago, Chile, CEPAL.

HANSon, M. (1997): Educational Decentralization: Issues and Challenges, Washington D.C., PREAL.

- (1999): «Editorial», en Educational Decentralization Around the Pacific Rim, International Conference Hosted by the Comparative Education Research Centre of the University of Hong Kong.

HEVIA, R. (1991): Política de descentralización de la Educación Básica y Media en América Latina. Santiago, Chile, OREALC, REDUC. 
LATORRE, L.; NÚÑEZ, I.; GonZÁLEZ, L. E. y HEVIA, R. (1991): La municipalización de la Educación: una mirada desde los administradores del sistema, Santiago, Chile, PIIE.

MCGINN, N. y WELSH, T. (1999): «Decentralization of Education: why, when, what and how?», en Fundamentals of Educational Planning, París, UNESCO-International Institute for Educational Planning.

Moura CAStro, C. de y WoILfF, L. (2001): Public or Private Education for Latin America? That is the (False) Question, Washington D.C., Inter-American Development Bank

NARODOWSKI, M. y NORES, M. (2002): «Socio-economic Segregation with (without) Competitive Education Policies. A Comparative Analysis of Argentina and Chile», en Comparative Education, 38 (4), pp. 429-451.

Nosiglia, M. C. y TRIPPANo, S. (2000): «Estado y Educación en la Argentina de los '90", en Ponencia presentada en el encuentro del año 2000 de la Latin American Studies Association, Miami, marzo, pp. 16-18.

NúNEEZ, I.; CONTARDo, H. y CASTILlo, J. (1994): Sistema Educativo Nacional de Chile, Madrid: OEI.

PIIE (1991): La descentralización Educativa y sus desafíos, PIIE, Santiago, Chile.

Puelles, M. de (1993): «Estudio teórico sobre las experiencias de descentralización educativa», en Revista Iberoamericana de Educación, núm. 3, Madrid, OEI.

OEI.

PULFER, D. y VITAR, A. (1994): Sistema Educativo Nacional de Argentina, Madrid,

RePetto, F.; Ansolabehere, K.; Dufour, G.; LuPiCA, C.; PotenzA, F.y RodríGuez LARRETA, H. (2001): Transferencia educativa hacia las provincias en los años '90: un estudio comparado, Buenos Aires, Centro de Estudios para el Desarrollo Institucional-Fundación Gobierno y Sociedad, Fundación Grupo Sophia.

SCHIEFELBEIN, E. y SCHIEFELBEIN, P. (2000): «Three Decentralization Strategies in two Decades: Chile 1981-2000», Journal of Educational Administration, 38 (5), 412 425.

SENÉN, S. de (1994): «La descentralización educativa y el orden político: países unitarios y federales», en Proyecto Principal de Educación en América Latina y el Caribe, 33, Santiago, Chile, UNESCO

STROMQUIST, N. (2002): «Globalization, the I, and the Other», en Current Issues in Comparative Education, 4 (2).

TEDESCO, J. C. (1992): «Nuevas estrategias de cambio educativo en América Latina», en Proyecto Principal de Educación en América Latina y el Caribe, 28, Santiago, Chile, UNESCO.

UNESCO (2001): Situación Educativa de América Latina y el Caribe:19802000, Santiago, Chile, OREALC. 


\title{
Contactar
}

Revista lberoamericana de Educación

\author{
Principal OEI
}

